\title{
Effect of pyrolytic carbon interface thickness on microstructure and mechanical properties of lightweight zirconium boride modified carbon-bonded carbon fiber composites
}

\author{
Xianghong $\mathrm{Xu}^{\text {a }}$, Baosheng $\mathrm{Xu}^{\mathrm{b}}$, Changqing Hong ${ }^{\mathrm{c}, ~}{ }^{*}$, David Hui ${ }^{\mathrm{d}, ~ * *}$ \\ a State Key Laboratory of Nonlinear Mechanics (LNM), Institute of Mechanics, Chinese Academy of Sciences, Beijing 100190, PR China \\ ${ }^{\mathrm{b}}$ AML, Department of Engineering Mechanics, School of Aerospace Engineering, Tsinghua University, Beijing 100084, PR China \\ ' Science and Technology on Advanced Composites in Special Environment Laboratory, Harbin Institute of Technology, Harbin 150001, PR China \\ d Department of Mechanical Engineering, University of New Orleans, LA 70148, USA
}

\section{A R T I C L E I N F O}

\section{Article history:}

Received 8 March 2016

Received in revised form

29 March 2016

Accepted 30 March 2016

Available online 26 April 2016

\section{Keywords:}

A. 3-Dimensional reinforcement:

A. Ceramic-matrix composites (CMCs);

B. Mechanical properties;

C. Micro-mechanics

\begin{abstract}
A B S T R A C T
To improve the mechanical properties of carbon-bonded carbon fiber (CBCF) composites, they are firstly fabricated by chemical vapor deposited (CVD) pyrolytic carbon (PyC) coating layer on the carbon fiber surface, and then modified by zirconium boride $\left(\mathrm{ZrB}_{2}\right)$ using three cycles of precursor infiltration and pyrolysis (PIP) process. The effects of different PyC interface thickness on the microstructure and mechanical properties of $\mathrm{ZrB}_{2}$ modified PyC coated $\mathrm{CBCF}\left(\mathrm{PyC}-\mathrm{CBCF} / \mathrm{ZrB}_{2}\right)$ composites were studied and characterized. As the PyC thickness increased from 0.5 to $3.6 \mu \mathrm{m}$, the flexural properties of $\mathrm{PyC}-\mathrm{CBCF} /$ $\mathrm{ZrB}_{2}$ composites are noticeably enhanced in $x / y$ and $z$ direction, respectively. Mechanical enhancements for $\mathrm{PyC}-\mathrm{CBCF} / \mathrm{ZrB}_{2}$ composites are mainly attributed to the effective interface bonding between carbon fiber and PyC, crack deflection and branching within the laminar PyC layer and carbon fiber pullout from PyC interface coating.
\end{abstract}

๑) 2016 Elsevier Ltd. All rights reserved.

\section{Introduction}

Carbon-bonded carbon fiber (CBCF) composites possess many excellent properties such as low density, low thermal conductivity, low coefficient of thermal expansion (CTE), good resistance of irradiation and high temperature capability [1-4]. Although the deposition of external coatings on $\mathrm{CBCF}$ composites can prevent them from oxidation in oxidation-containing atmospheres, CBCF composites have a poor mechanical strength to meet the increasing demand of actual application [2]. Therefore, the enhancement of mechanical properties is crucial for CBCF composites used in high temperature and load-bearing environment.

To overcome these limits, many researchers have focused on the surface modification of carbon fibers to enhance the interfacial adhesion between carbon fibers and matrix. For example, Li et al. [3] studied the $\mathrm{C} / \mathrm{C}$ composites with in situ grown CNFs using natural gas as carbon source. The CNFs are beneficial to the

\footnotetext{
* Corresponding author. Tel./fax: +86 45186403016.

** Corresponding author.

E-mail addresses: hongcq@hit.edu.cn (C. Hong), DHui@uno.edu (D. Hui).
}

improvement of mechanical properties of $\mathrm{C} / \mathrm{C}$ composites due to bridging effect which redistributes the load while the cracks extend toward fibers or CNFs leading to higher toughness as the more complex crack propagation channels dissipate more energy. Lim et al. [4] succeeded to prepare $C / C$ composites with improved mechanical strength by using a precursor made of CNFs grafted on carbon microfilaments. The as-synthesized carbon nanofibers acted as a "solid glue" through the formation of numerous nano-and micro junctions between the microfilaments and exhibited high elasticity and strength compared to raw materials. Another method is to invite the preparation process on the mechanical properties of $\mathrm{C} / \mathrm{C}$ composites carried out by Weisshaus et al. [5]. The result indicated that the duration of graphitization tended to reduce compression strength of $\mathrm{C} / \mathrm{C}$ composites. It is generally accepted that effective interfacial carbon layers can be remarkable enhancement of mechanical properties for $\mathrm{C} / \mathrm{C}$ composites due to good thermal coefficient matching and remarkable mechanical property of interfacial carbon layers [6-9]. Especially for porous carbon-based composites, it can form a uniform thinner carbon layer on the carbon fiber surface by chemical vapor deposition (CVD), in which the pores provide the diffusion channel for gas containing carbon in a CVD process. 
In this work, pyrolytic carbon (PyC) modified porous $\mathrm{CBCFs}$ (PyC-CBCF) composites were fabricated by the formation of a PyC coating layer on the carbon fiber surface via a CVD method. And then, the lightweight $\mathrm{ZrB}_{2}$-modified PyC-CBCF (PyC-CBCF/ $/ \mathrm{ZB}_{2}$ ) composites were fabricated by polymeric precursor infiltration and pyrolysis (PIP). The main purpose of the paper is to investigate the effect of PyC interphase thickness on the mechanical strength and fracture behavior of porous $\mathrm{PyC}-\mathrm{CBCF} / \mathrm{ZrB}_{2}$ composites.

\section{Experimental}

The schematic illustration of the typical microstructure of $\mathrm{CBCF}$ composites and manufacturing process for $\mathrm{PyC}-\mathrm{CBCF} / \mathrm{ZrB}_{2}$ composites are shown in Fig. 1. As seen from Fig. 1(a)-(c), the CBCF composites consist of chopped carbon fiber network bonded together at the intersections of the fibers by discrete regions of vitreous carbon. In addition, the discontinuous carbon fibers are orientated into layers to form a 2D planar random structure at $x y$ direction $[10,11]$. The schematic illustration of manufacturing process for $\mathrm{PyC}-\mathrm{CBCF} / \mathrm{ZrB}_{2}$ composites is shown in Fig. $1(\mathrm{~d})-(\mathrm{g})$. Firstly, porous $\mathrm{PyC}-\mathrm{CBCF}$ composites were fabricated by the formation of a PyC coating layer on the carbon fiber surface via a CVD method (Fig. 1(d), (e)). And then, the lightweight PyC-CBCF/ZrB 2 composites were fabricated via a PIP process (Fig. 1(f), (g)).

\subsection{Starting materials}

Rayon-based carbon fiber (diameter of $75 \mu \mathrm{m}$ and length of $1 \mathrm{~mm}$ ) was purchased from Ji lin Ji yan High-tech Fibers Co., Ltd. (Jilin, China). Phenolic resin powder (PF4090, fineness >95\%/200 mesh) was obtained from the Holyspring chemical Co., Ltd. (Juxian, China). Polyethylene imine (PEI) with an average molecular weight of 10,000 was obtained from Aladdin Co. Ltd. (Shanghai, China). $\mathrm{ZrB}_{2}$-containing precursors was obtained from Institute of Process Engineering (Chinese Academy of Science, Beijing, China).

\subsection{Preparation of $C B C F$ composites}

CBCF composites were prepared using the classical pressure filtration procedure [12]. A $200 \mathrm{ml}$ aqueous solution consisting of $60 \mathrm{mg}$ PEI was subject to a vigorous stirring in a $250 \mathrm{ml}$ beaker, and $5 \mathrm{~g}$ short carbon fiber was then added slowly to the solution to form a water-based slurry. After stirring for $20 \mathrm{~min}$, the same weight of phenolic resin powder was added to the slurry and the slurry was stirred for another $30 \mathrm{~min}$ to achieve good dispersion of waterbased slurry. The water-based slurry was then poured into a cylindrical mould [13] to remove the water from the slurry under an appropriate pressure to obtain a desired density. The acquired wet billets were cured at $80^{\circ} \mathrm{C}$ for $2 \mathrm{~h}$ and $150{ }^{\circ} \mathrm{C}$ for $3 \mathrm{~h}$. Then the cured samples were carbonized at $1000^{\circ} \mathrm{C}$ in $\mathrm{Ar}$ for $1 \mathrm{~h}$. The $\mathrm{CBCF}$ composites with a density of $0.26 \mathrm{~g} / \mathrm{cm}^{3}$ and porosity of $84.71 \%$ were prepared.

\subsection{Preparation of $\mathrm{PyC}-\mathrm{CBCF}-\mathrm{ZrB}_{2}$ composites}

PyC was deposited on the fibers surface in CBCF framework by chemical vapor deposition (CVD) at $1200{ }^{\circ} \mathrm{C}$ using propane as carbon source. Three different PyC interface thicknesses of 0.5, 2.6 and $3.6 \mu \mathrm{m}$ were obtained by controlling deposition time for 30,100 and $150 \mathrm{~h}$, respectively. Ultimately, $\mathrm{PyC}-\mathrm{CBCF}$ composites with different interface thicknesses were impregnated into $\mathrm{ZrB}_{2}$ polymeric precursor to prepare $\mathrm{ZrB}_{2}$ modified $\mathrm{PyC}-\mathrm{CBCF}$ composites by a PIP method [2]. In a typical experiment, the PyC-CBCF composites were impregnated into $\mathrm{ZrB}_{2}$-containing polymeric precursor using a vacuum infiltration devise, drying at $80^{\circ} \mathrm{C}$ in a drying oven at $\mathrm{Ar}$ atmosphere. The pyrolysis was performed at a heating rate of $2{ }^{\circ} \mathrm{C} / \mathrm{min}$ to the desired temperature of $1500{ }^{\circ} \mathrm{C}$ for $2 \mathrm{~h}$ under flowing $\mathrm{Ar}$ atmosphere. The composites were densification by another two cycles of $\mathrm{ZrB}_{2}$-containing polymeric precursor infiltration and pyrolysis.

For comparison, CBCF composites without CVD PyC were fabricated by three cycles of $\mathrm{ZrB}_{2}$-containing polymeric precursor infiltration and pyrolysis under the same condition.
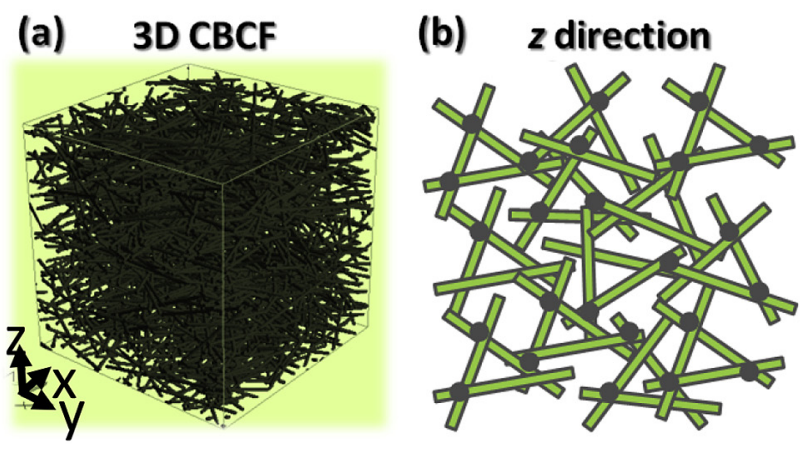

\section{(c) $x y$ direction}
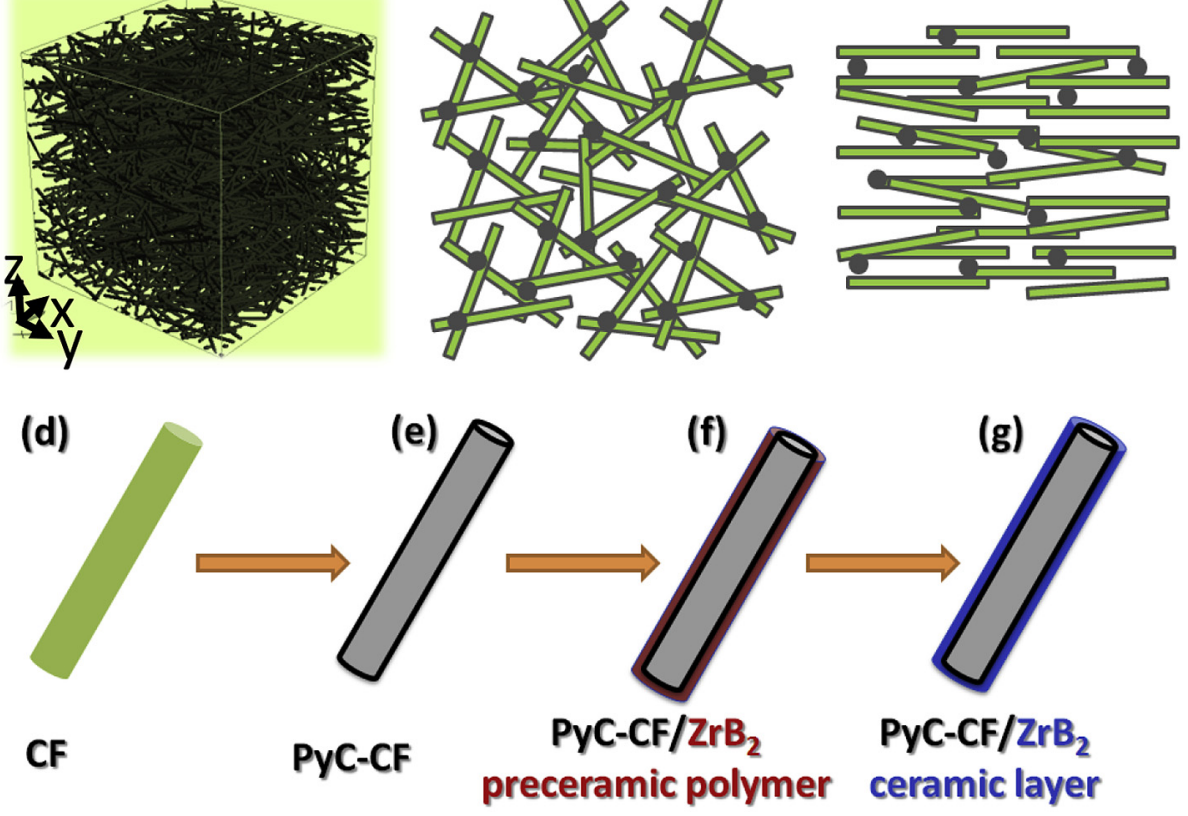

Fig. 1. Schematic illustration of the typical microstructure of $\mathrm{CBCF}$ composites and the manufacturing process for $\mathrm{PyC}-\mathrm{CBCF} / \mathrm{ZrB}{ }_{2}$ composites. 


\subsection{Characterization}

The phase composition of the $\mathrm{PyC}-\mathrm{CBCF}$ composites was investigated by a Rigaku $\mathrm{D} / \mathrm{max}-\mathrm{Rb} \mathrm{X}$-ray diffraction (XRD). The morphology of the composites was investigated by a Holland FEI Sirion scanning electron microscopy (SEM). The samples for threepoint bending tests were machined from bigger blocks and the effective size of the samples was $3 \times 4 \times 36 \mathrm{~mm}^{3}$. The span used to be $20 \mathrm{~mm}$ and a crosshead speed of $0.5 \mathrm{~mm} / \mathrm{min}$ was utilized during all tests. Samples were tested parallel to the $x / y$ and $z$ axes with the mechanical property anisotropy ratio being defined as the ratio of mechanical property values in the $x / y$ and $z$ planes.

\section{Results and discussion}

\subsection{PyC coated $C B C F$ composites}

Fig. 2 shows the microstructures of PyC coated carbon fiber with different deposition time. When deposition time increases from $30 \mathrm{~h}$ to $150 \mathrm{~h}$, the PyC interface thickness increases from 0.5 to $3.6 \mu \mathrm{m}$ according to the cross-section morphology (Fig. 2(a), (c) and (e)). The surface of carbon fiber transforms from rough to smooth shape with the increasing of PyC thickness (Fig. 2(b), (d) and (f)). Furthermore, the PyC coated CBCF is oriented preferentially and arranged randomly in the $z$ direction (Fig. 2(h), (j) and (l)) and perpendicular to $z$ axis in the $x / y$ direction (Fig. 2(g), (i) and (k)) due to the consequence of the vacuum or pressured molding process [13]. Clearly, the porosity of PyC coated CBCF both in $x / y$ and $z$ direction decreases with the deposition time and the PyC distributed uniformly on the surface of CBCF composites. Table 1 summarizes the density and porosity of PyC coated CBCF composites. The density for composites increases from 0.26 to $0.67 \mathrm{~g} / \mathrm{cm}^{3}$ and the open porosity decreases from 84.71 to $54.9 \%$ as the deposition time increased.

The XRD patterns of virgin $\mathrm{CBCF}$ and PyC coated CBCF composites are shown in Fig. 3. Due to the virgin CBCF containing lowgraphitization rayon carbon fiber framework, a turbostratic carbon structure exists corresponding to the appearance of (002), (103) and (110) broad diffraction peak [14,15]. However, it is clear that the (002) peak intensity becomes sharper as the increasing of the PyC thickness, because the increase of deposition time enhances the good graphitization of $\mathrm{PyC}$ compared to that of virgin carbon fiber.

The $\mathrm{ZrB}_{2}$ modified $\mathrm{PyC}-\mathrm{CBCF}$ composites were prepared by a precursor infiltration and pyrolysis method. The densification of $\mathrm{ZrB}_{2}$ modified $\mathrm{PyC}-\mathrm{CBCF}$ composites increases and most pores in $\mathrm{PyC}-\mathrm{CBCF}$ composites are filled and blocked by $\mathrm{ZrB}_{2}$ ceramic and the ceramic are coated on the carbon fibers and PyC interface surface (shown in Fig. S1). Table 2 shows the density and porosity of
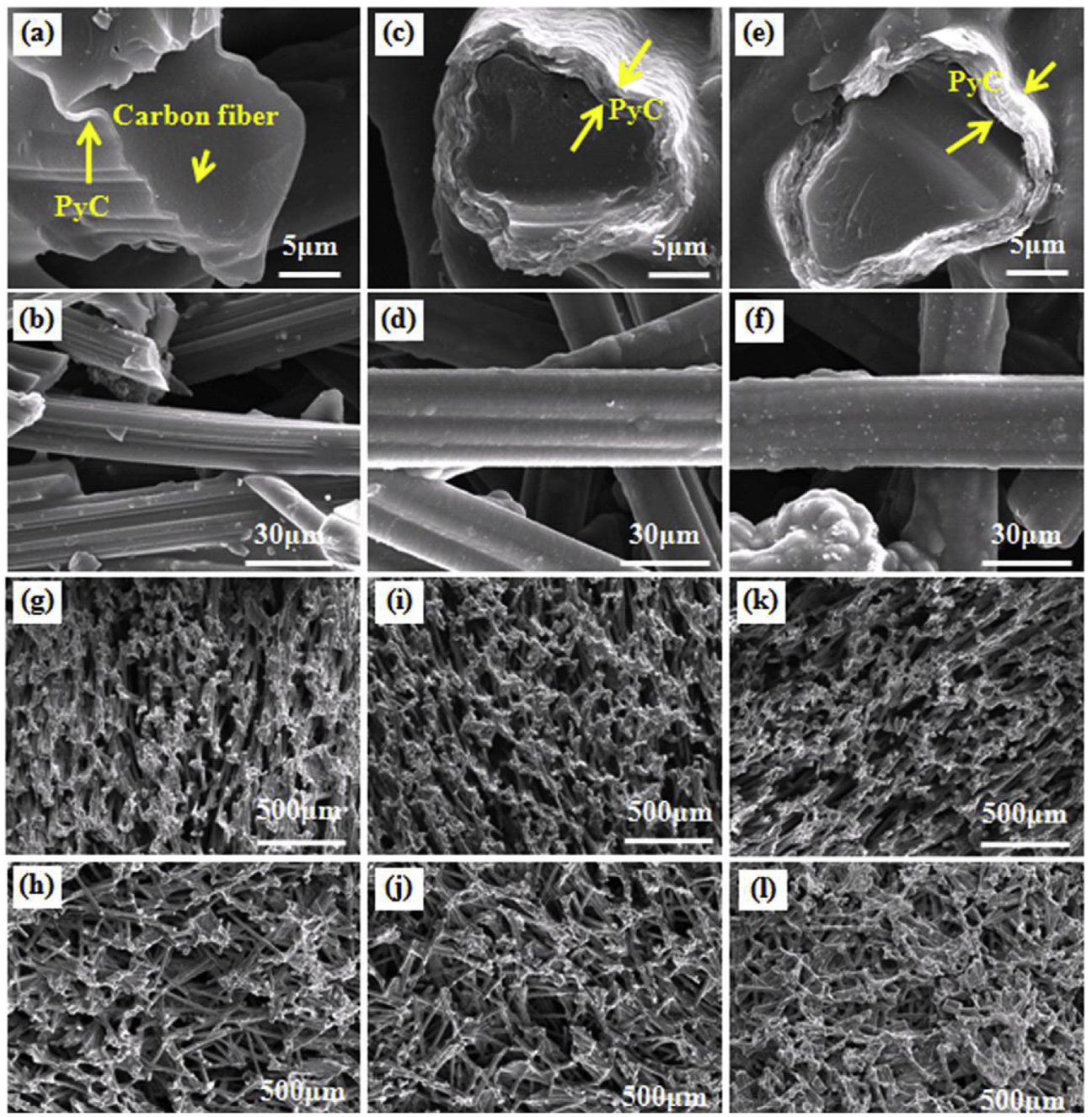

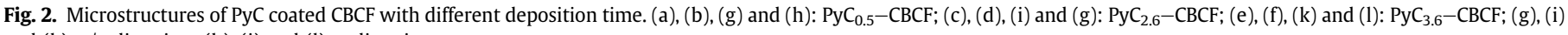
and $(\mathrm{k}): x / y$ direction; $(\mathrm{h}),(\mathrm{j})$ and $(\mathrm{l}): z$ direction. 
Table 1

Density and porosity of PyC modified CBCF composites.

\begin{tabular}{lcccc}
\hline & $\mathrm{CBCF}$ & $\mathrm{PyC}_{0.5}-\mathrm{CBCF}$ & $\mathrm{PyC}_{2.6}-\mathrm{CBCF}$ & $\mathrm{PyC}_{3.6}-\mathrm{CBCF}$ \\
\hline Deposition time (h) & 0 & 30 & 100 & 150 \\
Thickness of PyC & 0 & 0.5 & 2.6 & 3.6 \\
$\quad$ layer $(\mu \mathrm{m})$ & & & & 0.58 \\
Density $\left(\mathrm{g} / \mathrm{cm}^{3}\right)$ & 0.26 & 0.31 & 64.2 & 54.9 \\
Open porosity (\%) & 84.71 & 79.3 & & \\
\hline
\end{tabular}

PyC-CBCF $/ \mathrm{ZrB}_{2}$ composites with different PyC interface thickness. The density of $\mathrm{ZrB}_{2}$ modified $\mathrm{PyC}-\mathrm{CBCF}$ composites increases from 0.79 to $0.98 \mathrm{~g} / \mathrm{cm}^{3}$ and the porosity decreases from 48.5 to $38.8 \%$.

\subsection{Mechanical properties and fracture behavior}

The flexural properties of the $\mathrm{ZrB}_{2}$ modified $\mathrm{PyC}-\mathrm{CBCF}$ with different PyC interface thicknesses are shown in Fig. 4. It can be seen that the PyC interface can effectively improve the mechanical property of $\mathrm{CBCF} / \mathrm{ZrB}_{2}$ as shown in Fig. 4(a) and (b). The flexural strength of $\mathrm{CBCB} / \mathrm{ZrB}_{2}$ composites is 1.6 and $1.08 \mathrm{M}$ for $x / y$ and $z$ direction, respectively. When the PyC interface is introduced on the fiber surface, the composites significantly exhibit higher values in both $x / y$ and $z$ direction. The flexural strength of $\mathrm{PyC}_{0.5}-\mathrm{CBCF} / \mathrm{ZrB}_{2}$, $\mathrm{PyC}_{2.6}-\mathrm{CBCF} / \mathrm{ZrB}_{2}$ and $\mathrm{PyC}_{3.6}-\mathrm{CBCF} / \mathrm{ZrB}_{2}$ are $10.2,17.3$ and $17.9 \mathrm{MPa}$ for $x / y$ direction, respectively, and 6.9, 13.6 and $16.0 \mathrm{MPa}$ for $z$ direction, respectively, which obtained $1018.75 \%$ and $1354.5 \%$ improvement compared with $\mathrm{CBCF} / \mathrm{ZrB}_{2}$. Moreover, the flexural modulus also has been significantly improved from 164 to $2028 \mathrm{MPa}$ and from 57 to $1535 \mathrm{MPa}$ for $x / y$ direction and $z$ direction, respectively.

Fig. 4(c) and (d) shows the typical flexural stress/strain curves for $\mathrm{CBCF} / \mathrm{ZrB}{ }_{2}$ and $\mathrm{PyC}-\mathrm{CBCF} / \mathrm{ZrB}_{2}$ with different $\mathrm{PyC}$ interface thicknesses. It is interesting to note that the PyC interface increases the flexural strain, especially for PyC interface thickness of $0.5 \mu \mathrm{m}$ which increases the strain from $0.98 \%$ to $1.24 \%$ as shown in Fig. 4(c). Moreover, it is notable for the $z$ direction that flexural strain increases with the increasing the PyC interface thickness as shown in Fig. 4(d). The mismatch between the thermal expansion coefficient of ceramic coatings and carbon fibers results in cracking along the interface between fibers and ceramic. Hence, the brittle ceramic coatings are easily peeled off from fibers as preparation of test samples. Therefore, it is weaker surface strength of $\mathrm{CBCF} / \mathrm{ZrB}_{2}$ as a result of fractures prior to reaching the maximum stress value (see

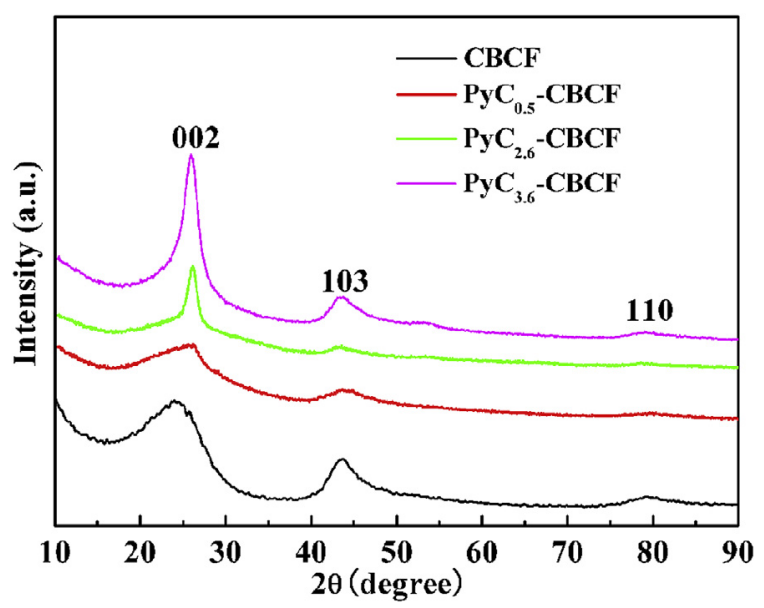

Fig. 3. $\mathrm{XRD}$ spectra of original $\mathrm{CBCF}$ composites and $\mathrm{PyC}-\mathrm{CBCF}$ composites with different deposition time.
Table 2

Density and porosity of modified $\mathrm{PyC}-\mathrm{CBCF} / \mathrm{ZrB}_{2}$.

\begin{tabular}{lccc}
\hline Samples & $\mathrm{PyC}_{0.5}-\mathrm{CBCF} / \mathrm{ZrB}_{2}$ & $\mathrm{PyC}_{2.6}-\mathrm{CBCF} / \mathrm{ZrB}_{2}$ & $\mathrm{PyC}_{3.6}-\mathrm{CBCF} / \mathrm{ZrB}_{2}$ \\
\hline PyC thickness $(\mu \mathrm{m})$ & 0.5 & 2.6 & 3.6 \\
Density $\left(\mathrm{g} / \mathrm{cm}^{3}\right)$ & 0.79 & 0.91 & 0.98 \\
Porosity $(\%)$ & 48.5 & 40.1 & 38.8 \\
\hline
\end{tabular}

insert in Fig. 4(c)) even at the starting stage of loading (insert in Fig. 4(d)). However, the $\mathrm{PyC}-\mathrm{CBCF} / \mathrm{ZrB}_{2}$ does not present this fracture behavior, suggesting that the PyC interface enhances the CBCF composites framework. On the other hand, it is indicated that the introduction of $\mathrm{ZrB}_{2}$ ceramic leads to the increase of brittle fracture of the sample as seen from Fig. 4(c) and (d).

It is clear that PyC interface plays some role in the mechanical reinforcement process [16]. So, the fracture surfaces of different samples failed in flexural tests are present to understand this fracture behavior as shown in Fig. 5. The ceramic coated fiber bundles in the different samples exhibit pulling-out behavior, presenting "gaps" or "peaks" feature on the fractured surface (Fig. 5(a), (c), (e) and (g)). The "gaps" tends to bigger for the $\mathrm{PyC}_{3.6}-\mathrm{CBCF} / \mathrm{ZrB}_{2}$ due to the strong adhesive force among fibers with a thicker PyC interface as seen in Fig. 5(g). Fig. 5(b), (d), (f) and (h) shows the fracture surfaces of the coated fibers with different thickness of PyC interface. As seen from Fig. 5(b), the $\mathrm{ZrB}_{2}$ ceramic layer shows a brittle fracture [17,18], and the carbon fiber present irregular fracture surface which increases the impact damage tolerance [19]. In addition, interfaces between fiber and ceramic layer exhibit debonding characteristic. It is interestingly found that the coated layer is visible plastic deformation when the $\mathrm{PyC}$ thickness is $0.5 \mu \mathrm{m}$ (Fig. 5(d)), indicating that the coated layer appears plastic tension strain before the failure of the composites. It is very likely that a similar failure mechanism reported by Della Bona and co-workers [20] who pointed out that the ceramic core surface was placed under tensile stress during the flexural testing of multilayer structures. The carbon fiber with a thin PyC interface $(0.5 \mu \mathrm{m})$ also presents an irregular fracture surface which indicates that the most of the energy from the load transmit through the thin $\mathrm{PyC}$ interface to carbon fiber and generate and expanse of cracks within carbon fiber. The effect of PyC with a thin thickness of $0.5 \mu \mathrm{m}$ can increase the strain as shown in Fig. 4(c). When the PyC thickness increases to 2.6 and $3.6 \mu \mathrm{m}$, the carbon fiber pulls out from the coated PyC layer as shown in Fig. 5(f) and (h). Moreover, a very rigorous delamination within PyC interface can be seen in the insert image in Fig. 5(f) and (h). It is worthy to note that the PyC is present a laminar structure along the carbon fiber surface with deposition time during the CVD process [21-23]. Accordingly, the laminar PyC pullout from $\mathrm{PyC}$ layers, and the pullout increases with increasing of PyC thickness, which can enhance the mechanical properties of composites. Crack deflection and branching also occur within the laminar PyC interface as shown in insert image in Fig. 5(f) and (h), because the driving force for interfacial crack growth equals the fracture energy of the interface at a lower load than that required for the driving force of the penetrating crack to the fracture energy of the matrix [24]. For the PyC interface with thickness of 2.6 and $3.6 \mu \mathrm{m}$ coated carbon fibers, the PyC interfacial crack release energy might increase and the cracks propagate through the adjacent PyC layers, leading to a fast and high energy fracture of carbon fibers, resulting in smooth and flat of fiber surface (Fig. 5(f) and (h)). As seen from Fig. 5(g) the mismatch of CET between PyC and ceramic result in forming interspaces which may influence the mechanical property of composites. Moreover, the strong interface bonding between carbon fiber and $\mathrm{PyC}$ due to better compatibility and obstinate PyC layer may lead to the brittle fracture for $\mathrm{CBCF}$ modified by PyC. 

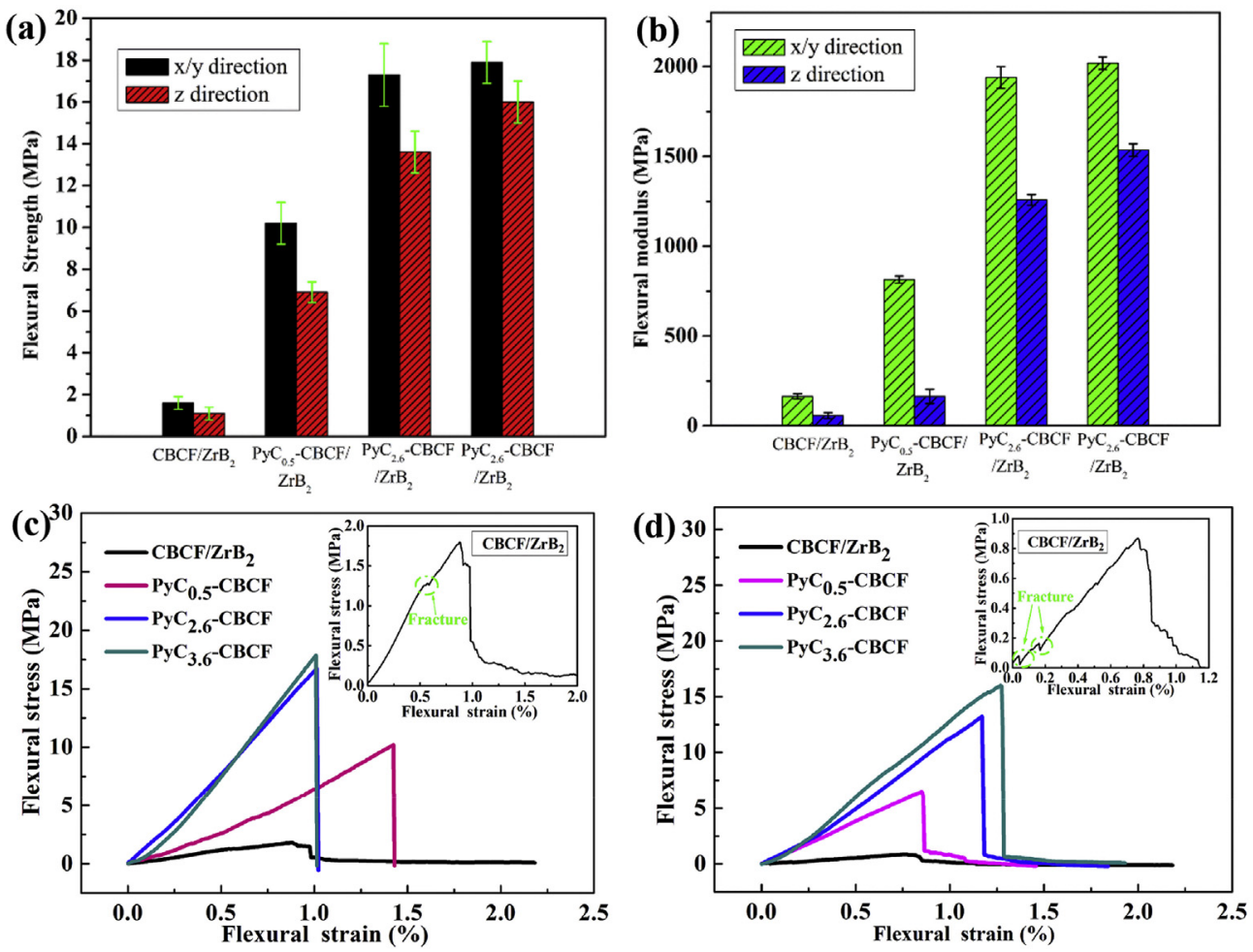

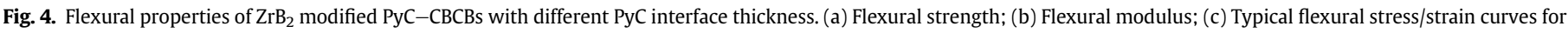

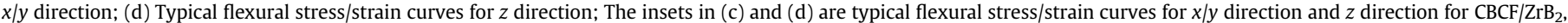
respectively.

To understand the effect of the ceramic layer on the mechanical enhancement of composites, the microstructures of fiber surfaces after three-point flexural tests were carried out by SEM as shown in Fig. 6. Fig. 6 shows the ceramic layer coated on the surface of the carbon fiber framework via a PIP process. The appearance of microcracks is found in Fig. 6, attributing to the shrinking of $\mathrm{ZrB}_{2}$ during PIP process and the mismatch of CET between carbon and ceramic. It is worthy to note that the ceramic layers peel from the fiber surface and PyC interface, which indicates the ceramic layers present a lower strength and brittle fracture behavior. The ceramic layer firstly can peel off from the carbon surface due to the weak bonding strength, and it makes a little contribution to the strength of PyC-CBCF/ZrB 2 composites. Moreover, compared to Fig. 6(c) and (d), the modified carbon fiber surface (Fig. 6(b)) presents the appearance of large area peeling, showing that the $\mathrm{PyC}-\mathrm{CBCF} / \mathrm{ZrB}_{2}$ composites with thinner PyC has larger plastic deformation than that with thicker PyC.

In addition, except for the fracture of single carbon fiber in the frameworks of composites as discussed former, the fiber bundles in the intersections of carbon fiber framework with different thickness of PyC interface also present different fracture behavior. Fig. S2 shows the SEM images of fracture surfaces for the intersections of the fibers with different thickness of PyC interface in PyC-CBCF/ $\mathrm{ZrB}_{2}$ composites. Clearly, the intersections of the fibers are coated by the continuous PyC interface. Fig. S2(a) presents relatively neatly fracture morphology between carbon fiber and PyC. In contrast, the carbon fiber bundles in intersections are all present pullout from $\mathrm{PyC}$ interface resulting in the irregular fracture morphology in Fig. S2(b) and (c), which is vital for increasing the strength of $\mathrm{PyC}-\mathrm{CBCF} / \mathrm{ZrB}_{2}$ composites. Compared with the PyC layers with $2.6 \mu \mathrm{m}$ (as seen in Fig. 5(f) and Fig. 6(c)), the PyC layer with $3.6 \mu \mathrm{m}$ (as seen in Fig. 5(h) and Fig. 6(d)) shows much more significant pullout behavior due to the thicker of the PyC layers. Additionally, the lower porosity is helpful to the improvement of mechanical properties (as shown in Table 2), for example, the examined mechanical strength of $\mathrm{PyC}_{3.6}-\mathrm{CBCF} / \mathrm{ZrB}_{2}$ is higher than that of $\mathrm{PyC}_{2.6}-\mathrm{CBCF} / \mathrm{ZrB}_{2}$.

\section{Conclusions}

Carbon-bonded carbon fiber frameworks were modified by PyC coating layer by a CVD process and then the $\mathrm{ZrB}_{2}$ modified $\mathrm{PyC}-\mathrm{CBCF}$ was prepared by a PIP method. The PyC interface with a thickness of $0.5,2.6$ and $3.6 \mu \mathrm{m}$ was obtained by controlling deposition time. Induced PyC interface strongly dominates mechanical properties and fracture behaviors for $\mathrm{ZrB}_{2}$-modified PyC-CBCF composites.

(1) The mechanical properties of $\mathrm{PyC}-\mathrm{CBCF} / \mathrm{ZrB} \mathrm{B}_{2}$ increase with the thickness of PyC interface. As the PyC thickness increased from 0.5 to $3.6 \mu \mathrm{m}$, the flexural strength noticeably elevated from 1.6 to $17.9 \mathrm{MPa}$ and $1.10-16.00 \mathrm{MPa}$ in $x / y$ direction and $z$ direction, respectively.

(2) The PyC interface presents laminar structure along the carbon fiber surface with different thickness and shows different fracture behavior. The PyC interface with $0.5 \mu \mathrm{m}$ thickness shows plastic deformation during flexural test. However, for PyC layer with 2.6 and $3.6 \mu \mathrm{m}$ thickness show pulling-out behavior, and crack deflection and branching occur within the laminar PyC interface.

(3) The carbon fiber has a good compatibility with PyC resulting in strong interaction between fibers and PyC layer, leading to brittle fracture behavior of $\mathrm{PyC}-\mathrm{CBCFs} / \mathrm{ZrB}_{2}$ composite compared to $\mathrm{CBCFs} / \mathrm{ZrB}_{2}$ composite. 

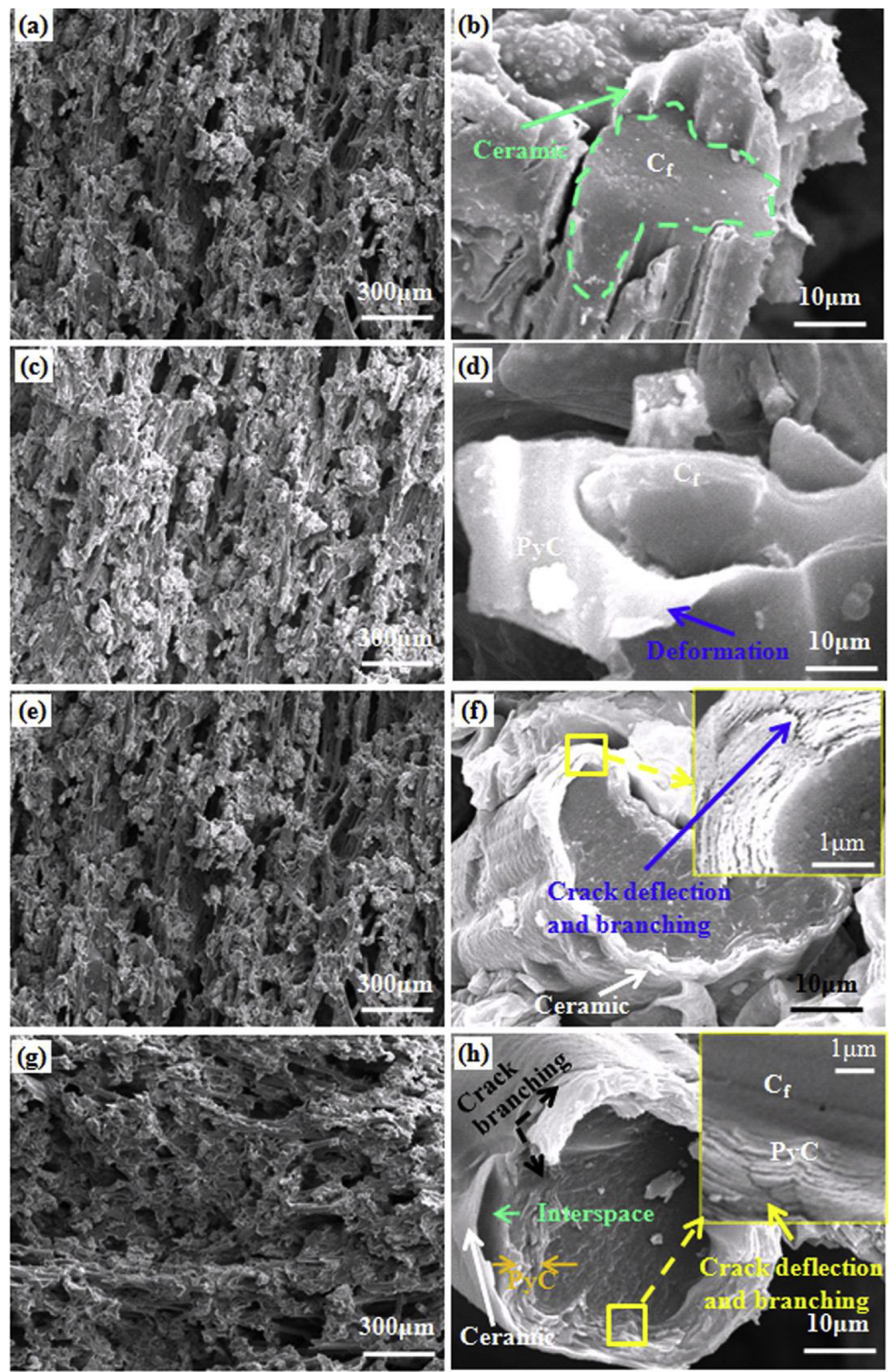

Fig. 5. SEM images of fracture surfaces after three-point bending tests. (a) and (b) $\mathrm{CBCF} / \mathrm{ZrB}_{2}$; (b) and (c) $\mathrm{PyC}_{0.5}-\mathrm{CBCF} / \mathrm{ZrB}_{2}$; (d) and (e) $\mathrm{PyC} \mathrm{C}_{2.6}-\mathrm{CBCF} / \mathrm{ZrB} 2$; (g) and (h) $\mathrm{PyC} \mathrm{C}_{3.6}-\mathrm{CBCF} /$ $\mathrm{ZrB}_{2}$. 

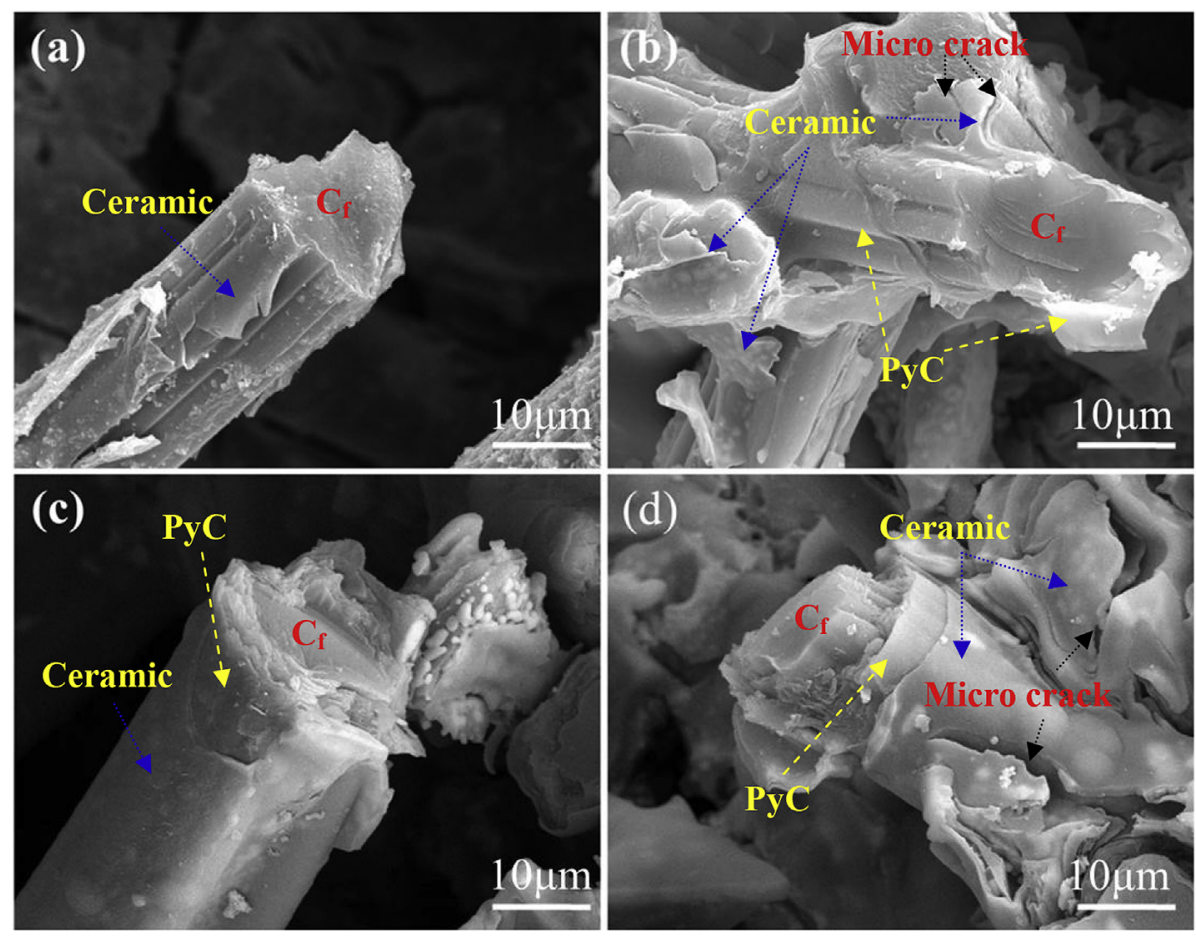

Fig. 6. $S E M$ images of fiber surfaces after three-point bending flexural tests. (a) $\mathrm{CBCF} / \mathrm{ZrB} 2$; (b) $\mathrm{PyC}_{0.5}-\mathrm{CBCF} / \mathrm{ZrB}_{2}$; (c) $\mathrm{PyC}_{2.6}-\mathrm{CBCF}_{2} \mathrm{ZrB} \mathrm{B}_{2}$; (d) $\mathrm{PyC} \mathrm{C}_{3.6}-\mathrm{CBCF} / \mathrm{ZrB} \mathrm{B}_{2}$

\section{Acknowledgments}

Financial support was provided by the National Natural Science Foundation of China (Project Nos. 51272056 and 11272313) and the National Fund for Distinguished Young Scholars (No: 51525201).

\section{Appendix A. Supplementary material}

Supplementary material associated with this article can be found, in the online version, at http://dx.doi.org/10.1016/j.compositesb. 2016.03.094.

\section{References}

[1] Davies IJ, Rawlings RD. Mechanical properties in compression of CVI-densified porous carbon/carbon composite. Compos Sci Technol 1999;59(1):97-104.

[2] Xu BS, Zhou SB, Hong CQ, Zhang XH, Han JC. Fabrication and properties of lightweight $\mathrm{ZrB}_{2}$ and $\mathrm{SiC}$-modified carbon bonded carbon fiber composites via polymeric precursor infiltration and pyrolysis. RSC Adv 2014;4(87): 47106-13.

[3] Li HL, Li HJ, Lu JH, Li KZ, Sun C, Zhang DS . Mechanical properties enhancemen of carbon/carbon composites by in situ grown carbon nanofibers. Mater Sci Eng A Struct 2012;547(15):138-41.

[4] Lim DS, An JW, Lee HJ. Effect of carbon nanotube addition on the tribological behavior of carbon/carbon composites. Wear 2002:252(5):512-7.

[5] Weisshaus H, Kenig S, Sivegmann A. Effect of materials and processing on the mechanical properties of C/C composites. Carbon 1991;29(8):1203-20.

[6] Ai SG, Fang DN, He RJ, Pei YM. Effect of manufacturing defects on mechanical properties and failure features of $3 \mathrm{D}$ orthogonal woven $\mathrm{C} / \mathrm{C}$ composites. Composites Part B Eng 2015;71:113-21.

[7] Boroujeni AY, Tehrani M, Nelson AJ, Al-Haik M. Hybrid carbon nanotube-carbon fiber composites with improved in-plane mechanical properties. Composites Part B Eng 2014;66:475-83.

[8] Mahroug MEM, Ashour AF, Lam D. Tests of continuous concrete slabs reinforced with carbon fibre reinforced polymer bars. Composites Part B Eng 2014;66:348-57.

[9] Yu HJ, Zhou XG, Zhang W, Peng HX, Zhang CR. Mechanical behavior of $\mathrm{SiC}_{\mathrm{f}} / \mathrm{SiC}$ composites with alternating $\mathrm{PyC} / \mathrm{SiC}$ multilayer interphases. Mater Des 2013;44:320-4.
[10] Ahmed AS, Rawlings RD, Ellacott SD, Boccaccini AR. Microstructural and compositional characterisation of the pyrocarbon interlayer in $\mathrm{SiC}$ coated low density carbon/carbon composites. J Eur Ceram Soc 2011;31(1):189-97.

[11] Baxter RI, Rawlings RD, Iwashita N, Sawada Y. Effect of chemical vapor infiltration on erosion and thermal properties of porous carbon/carbon composite thermal insulation. Carbon 2000;38(3):441-9.

[12] Xu BS, Zhou SB, Hong CQ, Zhang XH, Han JC. Fabrication and properties of lightweight $\mathrm{ZrB}_{2}$ and $\mathrm{SiC}$-modified carbon bonded carbon fiber composites via polymeric precursor infiltration and pyrolysis. RSC Adv 2014;4(87): 47106-13.

[13] Liu C, Han JC, Zhang XH, Hong CQ, Du SY. Lightweight carbon-bonded carbon fiber composites prepared by pressure filtration technique. Carbon 2013;59: $551-4$.

[14] Iwashita N, Park CR, Fujimoto H, Shiraishi M, Inagaki M. Specification for a standard procedure of X-ray diffraction measurements on carbon materials. Carbon 2004;42(4):701-14.

[15] Gerhard T, Friedrich C. Mechanical fastening of carbon composite tubes, numerical calculation of axial loading capacity and experimental verification. Composites Part B Eng 2014;67:391-9.

[16] Yang W, Noda T, Araki H, Yu J, Kohyama A. Mechanical properties of several advanced Tyranno-SA fiber reinforced CVI-SiC matrix composites. Mater Sci Eng A Struct 2003;345(1):28-35.

[17] Galan CA, Ortiz AL, Guiberteau F, Shaw LL. Crystallite size refinement of $\mathrm{ZrB}_{2}$ by high-energy ball milling. J Am Ceram Soc 2009;92(12):3114-7.

[18] Zhang XH, Xu L, Du SY, Han JC, Hu P, Han WB. Fabrication and mechanical properties of $\mathrm{ZrB}_{2}-\mathrm{SiCw}$ ceramic matrix composite. Mater Lett 2008;62(6): 1058-60.

[19] Wang Y, Liu HT, Cheng LF, Wang J. Interface engineering of fiber-reinforced all-oxide composites fabricated by the sol-gel method with fugitive pyrolytic carbon coatings. Composites Part B Eng 2015;75:86-94.

[20] Della Bona A, Anusavice KJ, DeHoff PH. Weibull analysis and flexural strength of hot-pressed core and veneered ceramic structures. Dent Mater 2003;19(7): 662-9.

[21] Mei $\mathrm{H}$, Zhang LT, $\mathrm{Xu}$ HR, Cheng LF, Damage mechanism of a carbon fiber ceramic composite during the step-loading indentation and its effect on the mechanical properties. Composites Part B Eng 2014;56:142-8.

[22] Bourrat X, Fillion A, Naslain R, Chollon G, Brendlé M. Regenerative laminar pyrocarbon. Carbon 2002;40(15):2931-45.

[23] Liao JQ, Huang BY, Huang ZF, Chen L, Chen T. Microstructural characterization of pyrocarbon-polarized light microscopic observation of anisotropy of pyrocarbon. Phys Test Chem Anal Part A Phys Test 2002;38:501-6.

[24] Li LB. A hysteresis dissipated energy-based damage parameter for life prediction of carbon fiber-reinforced ceramic-matrix composites under fatigue loading. Composites Part B Eng 2015;82:108-28. 